\title{
Numerical Investigation of Flow Structures for Four Buildings at Different Distances
}

\author{
Ahmet Fertelli ${ }^{1}\left(\mathbb{B}\right.$, Mehmet Balta ${ }^{2}$ \\ 'Department of Mechanical Engineering, Cumhuriyet University, Sivas, Turkey \\ ${ }^{2}$ Amasya University, Technical Sciences of Vocational School, Machine Program, Amasya, Turkey
}

\begin{abstract}
In the present study, it was aimed to compare the effects of the different distances between four buildings placed in a wind area on the surface pressure distributions and flow structures around the building. For this purpose, ANSYS-FLUENT 14.0 package program was used and analyses were performed with the RNG k- $\varepsilon$ turbulence model by 3D-modelling the buildings. The distances between the buildings were initially chosen as half of the building height and then the same as the building height. The average wind velocity was determined by taking the meteorological data for Sivas into consideration and the distributions of the flow line, velocity vector, turbulence kinetic energy and surface pressure coefficients were calculated for the medium height and roof level of the buildings. It is observed from the results that the distances between the buildings significantly affected the flow structures and velocity distributions, positive pressures were effective for front surfaces in the first buildings and negative pressure areas were formed in the rear surfaces and roofs.
\end{abstract}

Keywords: Wind effect, Tall building, Wind pressure coefficient, CFD

\section{INTRODUCTION}

Due to the housing problems of the urban population that emerged as a result of industrialization, high-rise apartments and housing estates became common in many cities. Positioning buildings appropriately by considering the effects of wind and pressure in the design phase of these structures and living spaces affect many parameters such as the flow structures created by different pressure areas, effects of natural ventilation and energy efficiency in heating and cooling.

Hui et al.[1], examined the effect of the flow between two rectangular and square buildings of the same height using experiments and the PIV method. Menga et al. [2] numerically examined the effects of different turbulence models, flow velocity and grid types on CAARC buildings. As a result of the analyses, it was observed that the flow separation, vortex and dead zone effects were directly affected by wind direction and caused a change in pressure. The maximum positive wind pressure coefficients occurred at a distance of approximately $0.8-0.85 \mathrm{H}$ to the wind surface and the maximum negative surface pressure occurred at the front side of the top surface. Tamura et al. [3] conducted researches in the wind tunnel in low, medium and high buildings from 0 to 90 degrees in 5-degree intervals and different wind directions. At the end of the experiment, the correlation of the absolute values of the wind force components was found to be substantial and significant. Zhaoa et al. [4] examined the characteristics of high pressure coefficients in high building walls and the effect of building shape on pressure coefficients. The effects of the height-width ratios and height-thickness ratios of oval-shaped building models on the pressure coefficient were examined. The results indicated that the windward side of the building was exposed to positive pressure while lateral, rear and top surfaces were in negative pressure areas. Xu et al. [5] performed a set of wind tunnel tests to examine the winds around 40 super high building models in various configurations including basic models of the same height, conical and triangular models, corner-modified models, composite models, spiral models and inclined models. It was observed that circular, corner chamfer, sharp-edged, spiral square and polygonal models produced the best results in terms of aerodynamics and wind characteristics. Hubova [6] examined the flow structures around two buildings placed in a boundary layer wind tunnel with obstacles and coarse elements of different heights inside. Mean velocity, turbulence intensity, integral length turbulence scale and power spectral densities were calculated in different wind directions. Wang et al. [7] exa- 
mined the flow pattern, wind capacity and wind energy on the canopy roof of a building. The maximum wind potential generated by the flow distribution on a reference building was determined using various heights, protrusions and the inclination angles of the canopy roof. In the results, it was found that there was no change under the flat canopy, that a slight change occurred when the protrusion was added, and that the best wind distribution was achieved in triangular canopy models with an inclination angle of $20^{\circ}$. Li et al. [8] experimentally examined the wind effects on the 88-storey Jin Mao Building in Shanghai, which is the tallest building in China with a height of 420.5 meters. Force coefficients for different wind directions, wind velocities and abruptly changing weather conditions were calculated by measuring power spectral densities and acceleration responses.

In the present study, the flow structures around four consecutive buildings placed both horizontally and vertically at different distances were examined. The streamline, velocity vector and turbulence kinetic energy changes around the buildings were presented in the analyses.

\section{MATERIAL METHOD}

The studied building is a building group in the form of a housing estate with 4 flats on each floor, 4 blocks and a total of 12 storeys [9]. In the analyses performed, the sizes of the buildings were reduced by $1 / 250$ and the model buildings were designed in the dimensions of $120 \times 100 \times 160 \mathrm{~mm}$ $(\mathrm{H})$. The purpose of building models is to achieve dynamic similarity, which is the ideal situation if the model size ratios are the same as the prototype. The building scale was determined in accordance with the studies in the literature. As shown in Figure 1, the distance between the consecutive buildings was displayed as $\mathrm{S}_{2}$ and the distance between the adjacent buildings was displayed as $\mathrm{S}_{1}$.
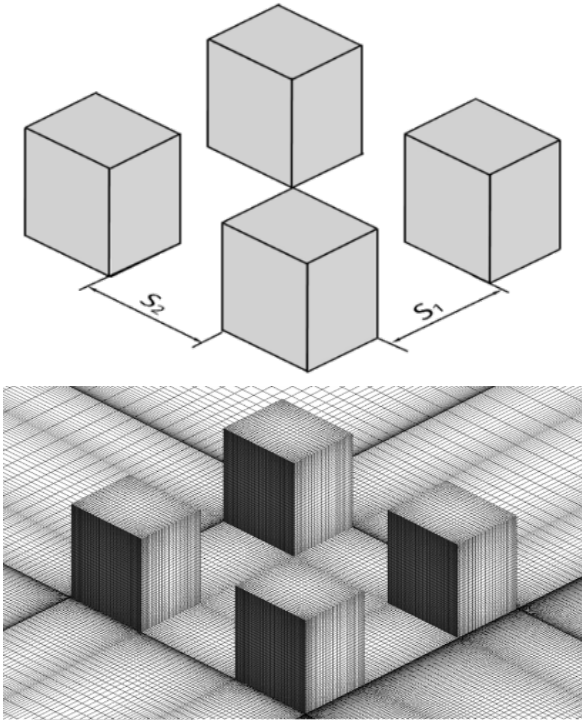

Figure 1. Building model and mesh structure

The distances between the buildings have been selected according to the Planned Areas Zoning Regulation for Turkey. Numerical calculations were made for two different distances: $\mathrm{S}_{1}=0.5 \mathrm{H}-\mathrm{S}_{2}=0.5 \mathrm{H}($ Model 1$)$ and $\mathrm{S}_{1}=\mathrm{H}-\mathrm{S}_{2}=\mathrm{H}$ (Model 2).
In the analyses, the mean velocity value was determined as $12 \mathrm{~m} / \mathrm{s}$ from the 10-year average meteorology values for Sivas [10] and the Reynolds number was calculated as 179000. The ANSYS-FLUENT 14.0 program was used for numerical calculations [10]. 4500000-5000000 quadrilateral elements (Figure 1) were used in the 3D analyses. Average skewness and mesh quality values for the elements were calculated as $1.095 \times 10^{-6}$ and 0.68064 . The RNG k- $\varepsilon$ turbulence model and Standard Wall Function [10] were preferred in the analyses as the flow was turbulent. At the end of the analyses, the flow movements at both medium and roof height of the building were obtained and the pressure distributions on the surfaces in all directions of the buildings were calculated.

\section{RESULT AND DISCUSSION}

Figure 2 shows comparison of the pressure coefficient values on the building with previous studies $[12,13]$. It is observed that the distributions of the pressure coefficients on the building surfaces were very close to each other.

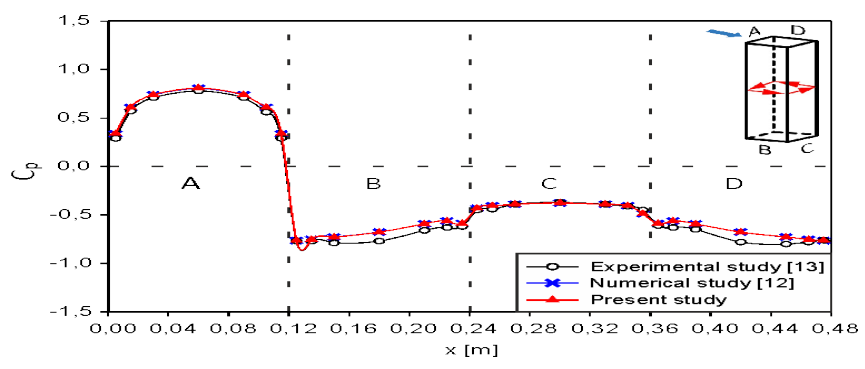

Figure 2. Comparison of the pressure coefficient values on the building with previous studies

Figure 3 shows the streamline, velocity vector and turbulence kinetic energy changes at heights of $y=0.08 \mathrm{~m}$ and $\mathrm{y}=0.016 \mathrm{~m}$ if the distances between the buildings are $\mathrm{S}_{1}=0.5 \mathrm{H}-\mathrm{S}_{2}=0.5 \mathrm{H}$. The flow to the front surfaces of the two front buildings were separated from the front corners of the buildings by moving upwards and downwards from the stagnation point in both buildings. The flow that was separated from the bottom corner of the building created the vortex rotating counterclockwise behind the building. The flow that was separated from the rear corner of the building below created the vortex rotating clockwise behind the building and merging with the vortex on the lower side surface. The vortex center is symmetrically located in the points $\mathrm{x} / \mathrm{h}=6.1$ and $\mathrm{z} / \mathrm{h}=0.3$. It was observed that there were flow separations on the outer side surface of the building although the flow continued without generating any vortexes. The flow that was separated from the top corner of the two buildings in the back created the large vortex rotating clockwise while the flow that was separated from the bottom corner created the small vortex rotating counterclockwise. The center points were determined as $\mathrm{x} / \mathrm{h}=7.5$ and $\mathrm{z} / \mathrm{h}=0.7$ for the large vortex and as $\mathrm{x} /$ $\mathrm{h}=7.6$ and $\mathrm{z} / \mathrm{h}=0.3$ for the small vortex. Maximum velocities occurred between the front two buildings due to jet flow. Turbulence kinetic energy was at the highest value in the bottom corner of the front top building and the top corner of the front bottom building. Apart from these areas, it was observed that the turbulence kinetic energy values around 

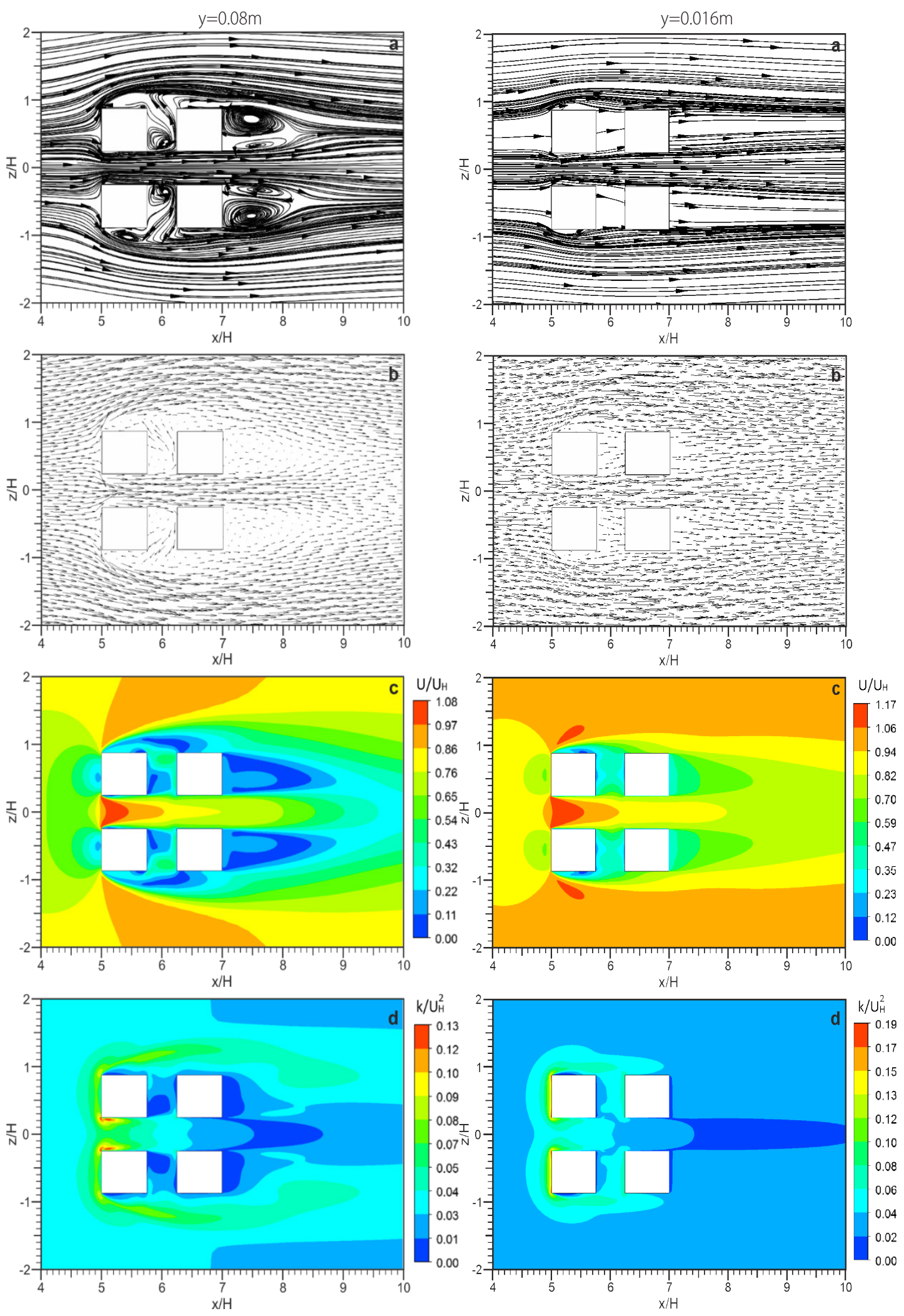

$\mathrm{x} / \mathrm{H}$

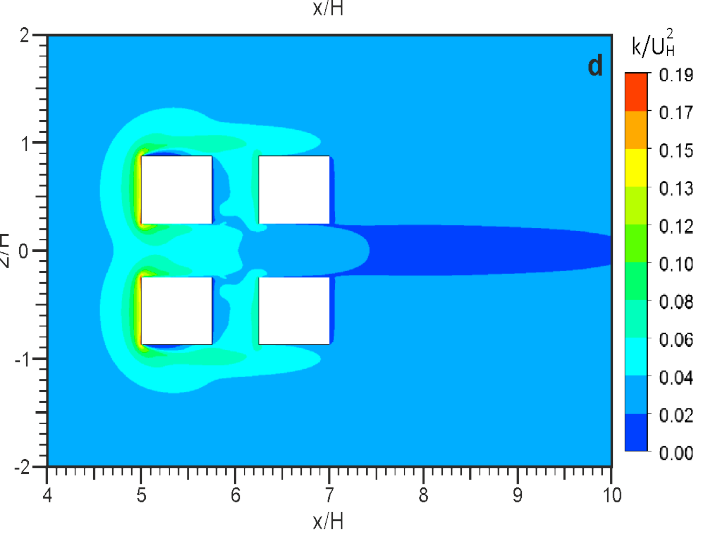

Figure 3. (a) Streamlines (b)velocity vectors (c)velocity distribution (d) turbulent kinetic energy for $\mathrm{S}_{1}=0.5 \mathrm{H}-\mathrm{S}_{2}=0.5 \mathrm{H}$ model

both the front and rear buildings decreased. When the flow conditions at roof height were examined (Figure 3, $y=0.016$ $\mathrm{m})$, it was observed that vortex formation did not occur.

While the highest velocity rate was 1.17 , minimum velocities with ongoing effects in a large area occurred on the side surfaces of the building. It was observed that both the maximum velocity and turbulence kinetic energy values were higher compared to the values at medium height and that the changes in the front buildings sustained their effect on the building in the back.

In the case of $\mathrm{S}_{1}=\mathrm{H}$ and $\mathrm{S}_{2}=\mathrm{H}$ (Figure 4 ), larger vortexes were formed behind the front building with the increase of the distance between the buildings and the symmetric vortexes that were formed in the rear buildings were at almost the same dimensions as the distance $\mathrm{S}_{1}=\mathrm{S}_{2}=0.5 \mathrm{H}$. Larger velocity zones were formed behind the front building and jet 

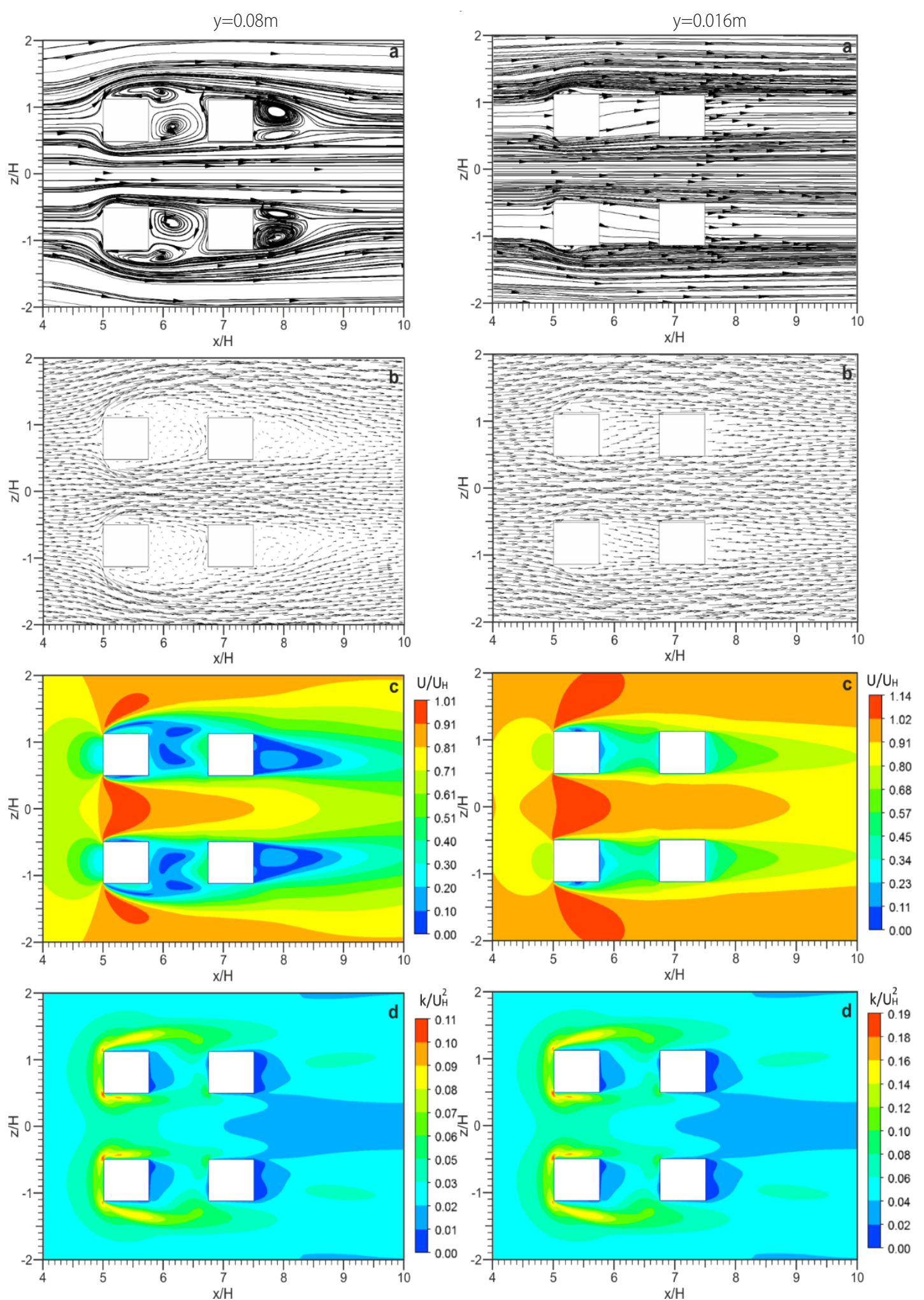

Figure 4. (a) Streamlines (b)velocity vectors (c)velocity distribution (d) turbulent kinetic energy for $\mathrm{S}_{1}=\mathrm{H}-\mathrm{S}_{2}=\mathrm{H}$ model

flow was observed here as well at a weaker level due to the vertical increase in the distance between the buildings. In this model, as can be observed from velocity distributions, the biggest velocity values were obtained in the top and bottom corners of the front building while the velocity changes on the buildings in the $\mathrm{S}_{1}=\mathrm{S}_{2}=0.5 \mathrm{H}$ model are smaller. When the turbulence kinetic energy changes were examined, it was observed that the area with the highest kinetic energy for the front building extended to the rear of the building. The changes in the rear building were observed as similar to the case of $\mathrm{S}_{2}=0.5 \mathrm{H}$. In roof height (Figure $4, \mathrm{y}=0.016 \mathrm{~m}$ ), it was observed that the maximum velocities effected a larger area in the top and bottom sections of the front buildings. Similarly to the kinetic energy changes at the half height of the building $(\mathrm{H} / 2)$, the turbulence kinetic energy changes at roof height $(\mathrm{H})$ were at high values in the upper and lower sections of the front buildings and very low values in the rear buildings .

Figure 5 shows the velocity and turbulence kinetic energy 
profiles of the models that were calculated at different points in the horizontal direction at the half-height level. Velocity values did not decrease in the wake region of the buildings and reverse flow zones were formed. It was observed that the velocity between the two buildings increased due to jet flow. It was observed that while velocity between the rear buildings increased in the case of $S_{1}=0.5$, this change in velocity occurred on the front side of the buildings with the increase in the distance. It was observed that the jet flow effect ended at the points $x / H=8$ and $x / H=9$ and the decrease in velocity continued. This reduction effect in velocity disappeared in the following points. In the turbulence kinetic energy profiles behind the model, turbulence
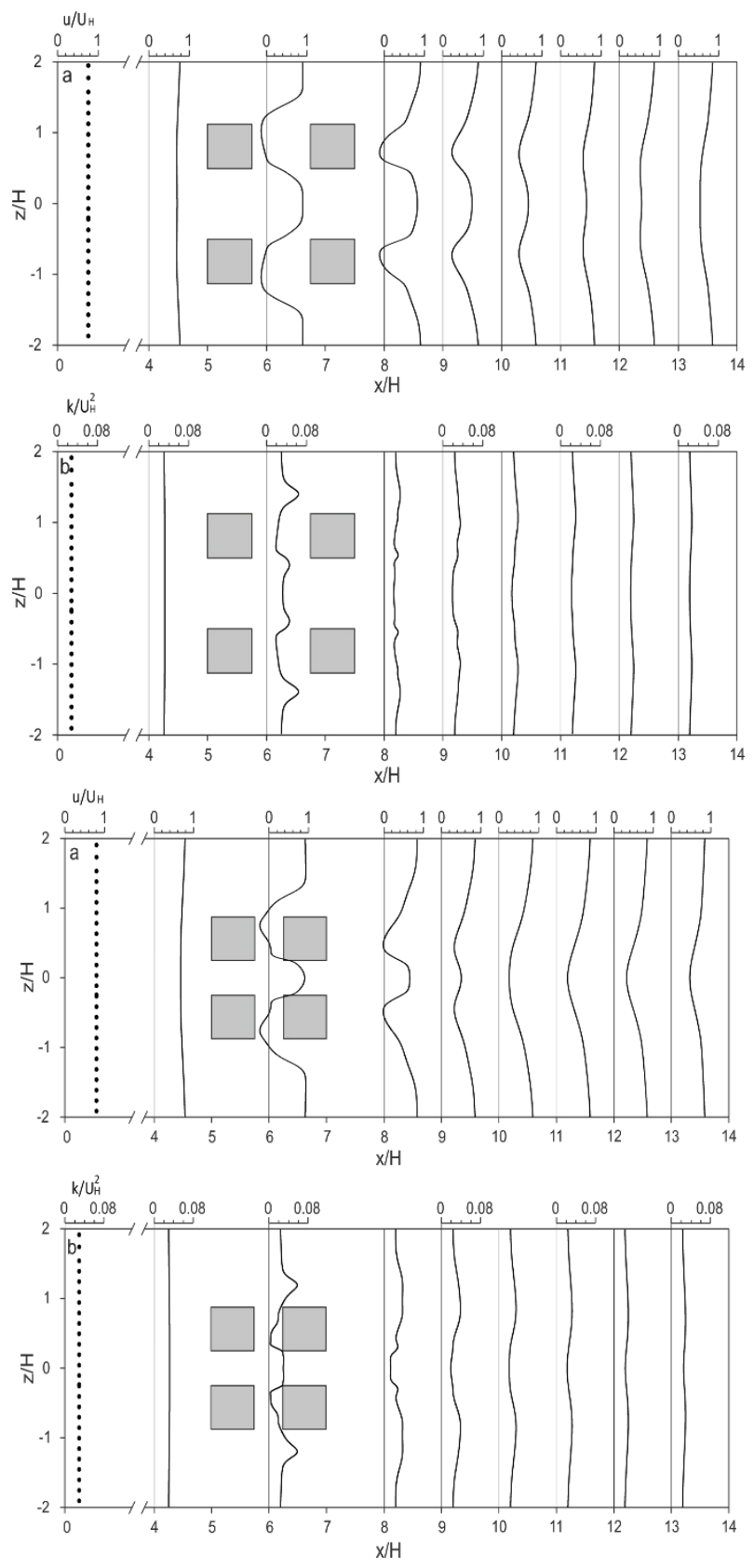

Figure 5. Velocity and kinetic energy distributions for building medium height a) Model $1 \mathrm{~S}_{2}=\mathrm{S}_{1}=0.5 \mathrm{H}$, b) Model $2 \mathrm{~S}_{1}=\mathrm{S}_{2}=\mathrm{H}$

kinetic energy values increased due to the turbulent boundary layer on the top side surface of the building above and the bottom side surface of the building below. This increase ended in the following positions behind the model.
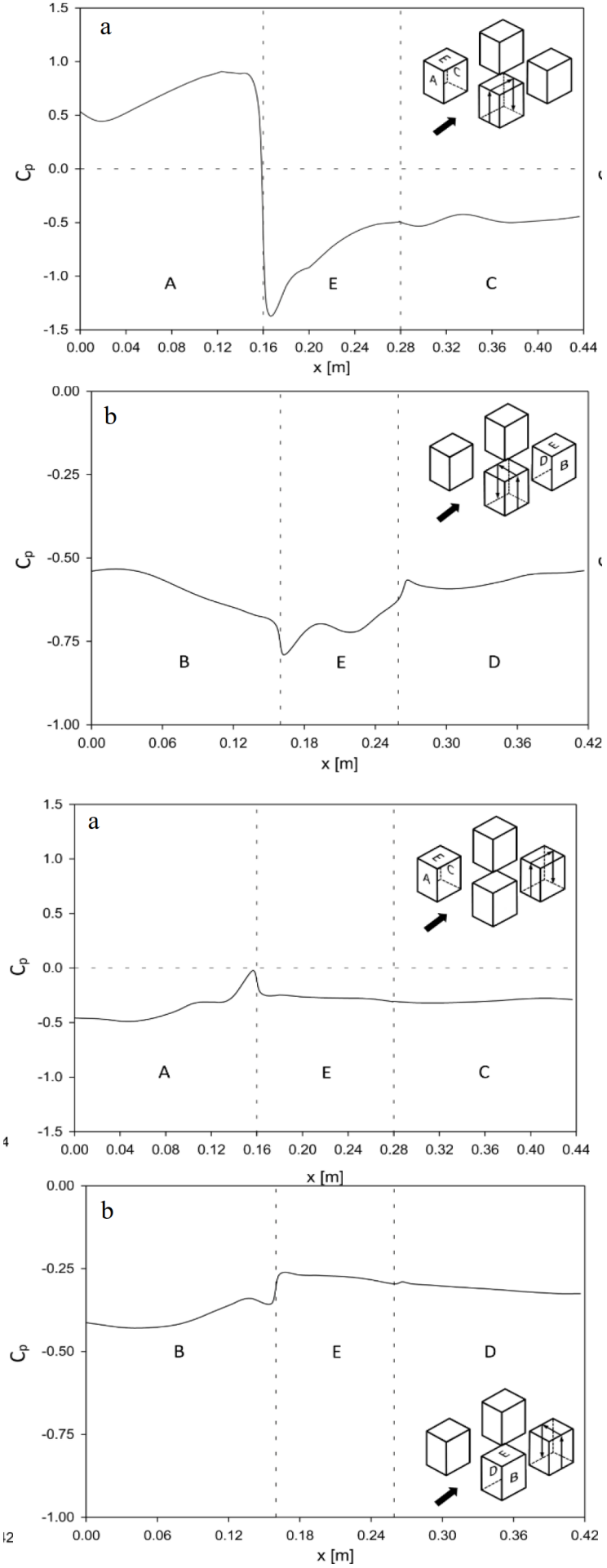

Figure 6. Pressure coefficients for the front and rear building in Model 1 $\left(\mathrm{S}_{1}=0.5 \mathrm{H}, \mathrm{S}_{2}=0.5 \mathrm{H}\right)$ a) Front, roof and rear surface $\left.(\mathrm{A}, \mathrm{E}, \mathrm{C}) \mathrm{b}\right)$ Side, roof and side surface $(\mathrm{B}, \mathrm{E}, \mathrm{D})$

Figures 6 and Figure 7 show the pressure distributions calculated along the middle-axis in the front $(\mathrm{A})$, roof $(\mathrm{E})$ and rear $(\mathrm{C})$ surfaces of the front and rear buildings. In the figure, it is observed that the pressure coefficients $\left(\mathrm{C}_{\mathrm{p}}\right)$ on the front (A) surface, which was directly exposed to wind, are in positive values and increase depending on height. The pressure coefficient was observed to be $C_{p}=-0.5$ in the rear building while the maximum value for the front building was $\mathrm{C}_{\mathrm{p}}=0.8$. It was observed that the critical pressure value was $C_{p}^{p}=-1.4$ for the front building and $C_{p}=-0.3$ for the rear bu- 

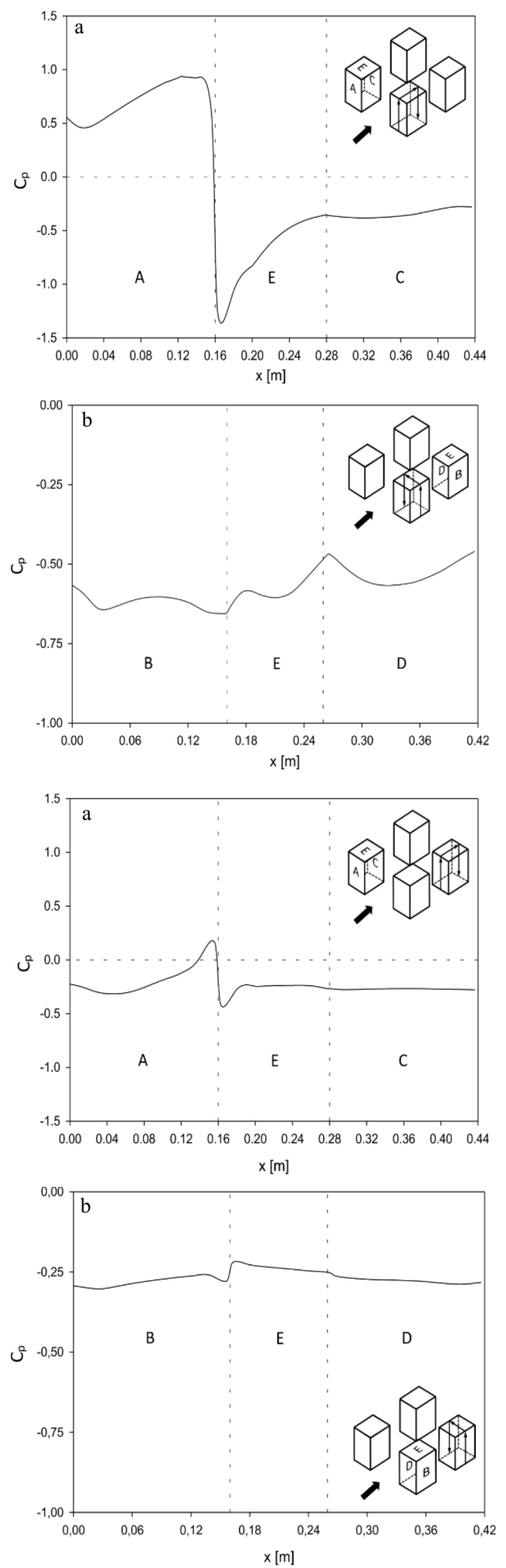

Figure 7. Pressure coefficients for the front and rear building in Model 2 $\left(S_{1}=H_{1} S_{2}=H\right)$ a) Front, roof and rear surface $(A, E, C)$ b) Side, roof and side surface $(B, E, D)$

ilding due to the flow that was separated from the front corner of the flat roof $(\mathrm{E})$ and the negative pressure coefficient progressively decreased along the middle-axis. On the rear (C) surface of the building, it was observed that the negative pressure coefficient value was $C_{p}=-0.5$ in the front building and $C_{p}=-0.3$ in the rear building. When the pressure distributions on the right (B), roof (E) and rear (D) surfaces on the front and rear buildings were examined, it was observed that the model side surfaces (B and D) and model roof (E) were fully under the influence of negative pressure. It was observed that the pressure coefficients on the rear building surface decreased compared to the front building with values of $C_{p}=-0.38$ in surface $B, C_{p}=-0.31$ in surface $E$ and $C_{p}=$ -0.35 in surface $D$. After the distance between the buildings was increased (Figure 7), it was observed that the pressure coefficients on the front surface of the first building were positive and increased depending on height as was the case in the model $\mathrm{S}_{1}=0.5 \mathrm{H}$ and $\mathrm{S}_{2}=0.5 \mathrm{H}$. The pressure coefficients on surface $C$ were higher compared to the previous model. The effect of negative pressure continued in surfaces $B, E$ and $\mathrm{D}$, and the pressure distribution calculated on surface $\mathrm{B}$ consisted of higher negative pressure coefficients compared to the other surfaces. In the model $\mathrm{S}_{1}=0.5 \mathrm{H}$ and $\mathrm{S}_{2}=0.5 \mathrm{H}$, while the lowest pressure coefficient in surface B was $\mathrm{C}_{\mathrm{p}}=$ -0.8 , the pressure coefficient on the same surface was calculated as $C_{p}=-0.65$ after the distance was increased.

\section{CONCLUSIONS}

In the present study, the flow structures, turbulence kinetic energy changes and pressure coefficients around four buildings that were placed at distances of $\mathrm{S}_{1}=0.5 \mathrm{H}-\mathrm{S}_{2}=0.5 \mathrm{H}$ and $\mathrm{S}_{1}=\mathrm{H}-\mathrm{S}_{2}=\mathrm{H}$ were examined. It was observed that vortex formation and the flow structures both on the rear building and between the two buildings were affected after the distance between the buildings was changed. It was seen that the positive pressure coefficient occurred only on the entire front surface of the first building while the front surface of the rear building was fully under the influence of negative pressure. Side surfaces (B and D), roof and rear surfaces (E and C) in all buildings are fully exposed to negative pressure. After the distance between the buildings was increased, the pressure coefficients decreased, particularly in surfaces A and B.

\section{ACKNOWLEDGMENTS}

The authors acknowledge the The Scientific Research Projects Council of Cumhuriyet University for the financial support of the project M-611.

\section{REFERENCES}

[1] Hui, Y., Tamura Y., Yoshida A., Kikuchi H. (2013). Pressure and flow field investigation of interference effects on external pressures between high-rise buildings. Journal of Wind Engineering \& Industrial Aerodynamics, 115:150-161, DOI: 10.1016/j.jweia.2013.01.012.

[2] Menga, F.Q., Heb, B.J., Zhub J., Zhaoc D.X., Darkod A., Zhaoe Z.Q. (2018). Sensitivity analysis of wind pressure coefficients on CAARC standard tall buildings in CFD simulations. Journal of Building Engineering, 16: 146-158. DOI: 10.1016/j.jobe.2018.01.004.

[3] Tamura, Y., Kim, C., Kikuchi, H., Hibi, K., (2014). Correlation and 
combination of wind force components and responses. J. Wind Eng.Ind.Aerodyn, 125: 81-93, DOI: /10.1016/j.jweia.2013.11.015.

[4] Zhaoa D.X.,, Heb B.J., (2017). Effects of architectural shapes on surface wind pressure distribution: Case studies of oval-shaped tall buildings. Journal of Building Engineering 12: 219-228, DOl: 10.1016/j. jobe.2017.06.009.

[5] Xu, X., Yang Q., Yoshida A., Tamura Y., (2017). Characteristics of pedestrian-level wind around super-tall buildings with various configurations. Journal of Wind Engineering \& Industrial Aerodynamics, 166: 61-73, DOI: 10.1016/j.jweia.2017.03.013.

[6] Hubova, O., Konecna L., (2016). Experimental Determination of Wind Flowing Around Building Configuration. Procedia Engineering, 161: 1845 - 1851, DOI: 10.1016/j.proeng.2016.08.701.

[7] Wang, B., Cot, L.D., Adolphe, L., Geoffroy, S., (2017). Estimation of wind energy of a building with canopy roof, Sustainable Cities and Society, 35: 402-416, DOI: 10.1016/j.scs.2017.08.026

[8] Li, Q.S., Fu J.Y., Xiao Y.Q., Li Z.N., Ni Z.H., Xie Z.N., Gu M. (2006), Wind tunnel and full-scale study of wind effects on China's tallest building. Engineering Structures, 28: 1745-1758, DOI: 10.1016/j.engstruct.2006.02.017.

[9] Balta M., (2016). Farklı yapılara sahip binalardaki akış yapılarının sayısal olarak incelenmesi. Cumhuriyet Üniversitesi, Fen Bilimleri Enstitüsü (Yüksek Lisans Tezi), Sivas.

[10] Sivas ili için meteorolojik veriler, Meteoroloji Genel Müdürlüğü, 2013.

[11] ANSYS 14, 2011. User Guide.

[12] Kaydok T., (2014). Farklı kesitlere sahip yüksek binalar üzerinde türbülanslı akışların sayısal incelenmesi. K.T.Ü. Fen Bilimleri Enstitüsü (Yüksek Lisans Tezi), 94s Trabzon.

[13] Hunte, S., (2010). Testing the application of CFD for building design. Delft University of Technology (Master Thesis), Netherland. 